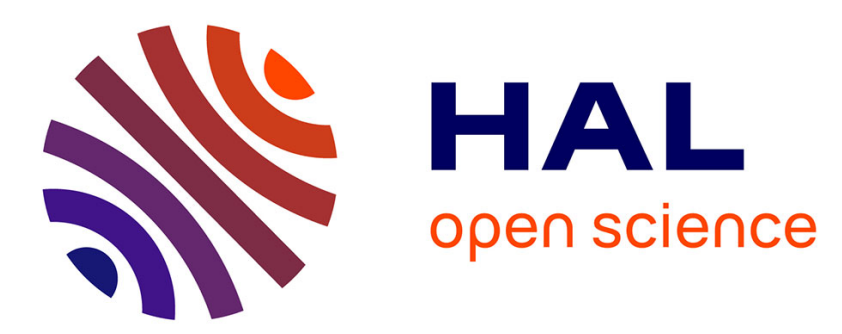

\title{
Structural and fluorescence properties of Ho3+/Yb3+ doped germanosilicate glasses tailored by Lu2O3
}

W. Cao, F. Huang, R. Ye, M. Cai, R. Lei, J. Zhang, S. Xu, X.-H. Zhang

\section{To cite this version:}

W. Cao, F. Huang, R. Ye, M. Cai, R. Lei, et al.. Structural and fluorescence properties of Ho3+/Yb3+ doped germanosilicate glasses tailored by Lu2O3. Journal of Alloys and Compounds, 2018, 746, pp.540-548. 10.1016/j.jallcom.2018.02.325 . hal-01740148

HAL Id: hal-01740148

https://hal-univ-rennes1.archives-ouvertes.fr/hal-01740148

Submitted on 6 Jul 2018

HAL is a multi-disciplinary open access archive for the deposit and dissemination of scientific research documents, whether they are published or not. The documents may come from teaching and research institutions in France or abroad, or from public or private research centers.
L'archive ouverte pluridisciplinaire HAL, est destinée au dépôt et à la diffusion de documents scientifiques de niveau recherche, publiés ou non, émanant des établissements d'enseignement et de recherche français ou étrangers, des laboratoires publics ou privés. 


\title{
Structural and fluorescence properties of $\mathrm{Ho}^{3+} / \mathrm{Yb}^{3+}$ doped germanosilicate glasses tailored by $\mathrm{Lu}_{2} \mathrm{O}_{3}$
}

\author{
Wenqian Cao ${ }^{1}$, Feifei Huang ${ }^{1 *}$, Renguang $\mathrm{Ye}^{12}$, Muzhi Cai ${ }^{12}$, Ruoshan Lei ${ }^{1}$, Junjie Zhang ${ }^{1}$, \\ Shiqing $\mathrm{Xu}^{1 *}$ and XiangHua Zhang ${ }^{2}$
}

1. College of Materials Science and Engineering, China Jiliang University, Hangzhou, 310018, China

2. Laboratoire Verres \& Céramiques, UMR CNRS 6226, Université de Rennes 1, Campus Beaulieu, 35042 Rennes Cedex, France

* Corresponding author. huangfeifei@cjlu.edu.cn

$$
\text { shiqingxu@cjlu.edu.cn. }
$$

ABSTRACT: Structural and fluorescence properties of $\mathrm{Ho}^{3+} / \mathrm{Yb}^{3+}$ co-doped germanosilicate glasses have been modified by tailoring the composition using lanthanide additive $\mathrm{Lu}_{2} \mathrm{O}_{3}$. $\mathrm{Raman}$ spectra and X-ray Photoelectron spectra reveal that the addition of $\mathrm{Lu}_{2} \mathrm{O}_{3}$ can change the structure by increasing non-bridging oxygens (NBO) in this glasses. Meanwhile, an improved thermal stability $(\Delta \mathrm{T}$ : from 110 to $187^{\circ} \mathrm{C}$ ) has also been obtained via $\mathrm{Lu}^{3+}$ 'lanthanide contraction'. Futhermore, the positive effect of changed glass structure gives excellent fluorescence properties by the decreasing cross relaxation process which are proved by the experimental upconversion, near-infrared and mid-infrared fluorescence spectra. Additionally, a double enhancement of a $2.0 \mu \mathrm{m}$ emission has been achieved successfully in this silica-germanate glass with $7 \mathrm{~mol} \% \mathrm{Lu}^{3+}$ addition, which possesses a larger emission cross section $\left(4.41 \times 10^{-21} \mathrm{~cm}^{2}\right)$ at $2022 \mathrm{~nm}$. These results indicate that the optimized emission of $\mathrm{Ho}^{3+}$ for optical fiber laser can be achieved by tuning the glass structure using lanthanide additive $\mathrm{Lu}_{2} \mathrm{O}_{3}$.

Keywords: Germanosilicate glasses; Lanthanide additive $\mathrm{Lu}_{2} \mathrm{O}_{3}$; $\mathrm{NBO}$ and $\mathrm{BO}$; Energy transfer. 


\section{Introduction}

Rare earth ions doped glass fibers that exhibit laser emission around $\sim 2.0 \mu \mathrm{m}$ have been paid considerable attention due to their potential applications in eye safe laser radar, atmosphere pollution monitoring, measurement of water vapor and biomedicine, etc[1-5]. A number of experiments have proved that $\mathrm{Tm}^{3+}$ and $\mathrm{Ho}^{3+}$ perform well in achieving $2.0 \mu \mathrm{m}$ laser. Compared with $\mathrm{Tm}^{3+}$, the emission band of $\mathrm{Ho}^{3+}$ is broader and the stimulated emission cross section of $\mathrm{Ho}^{3+}$ is practically five times larger than that of $\mathrm{Tm}^{3+}$, which suggests that more efficient laser output can be achieved by $\mathrm{Ho}^{3+}$. Meanwhile, the longer fluorescence lifetime of $\mathrm{Ho}^{3+}$ is conducive to Q-switched lasers[6, 7]. However, $\mathrm{Ho}^{3+}$ cannot directly be pumped by $808 \mathrm{~nm}$ or $980 \mathrm{~nm}$ commercial laser diode (LD) source for lacking of a suitable ground absorption band. Traditionally, in order to solve this problem, other rare earth ions such as $\mathrm{Er}^{3+}$, $\mathrm{Yb}^{3+}, \mathrm{Tm}^{3+}$ and $\mathrm{Nd}^{3+}$ with obvious ground absorption under commercial LD excitations are usually introduced to sensitize the $\mathrm{Ho}^{3+}[8-10]$. Among all the sensitizers, $\mathrm{Yb}^{3+}$ ion with the simple energy level structure (ground state ${ }^{2} \mathrm{~F}_{7 / 2}$ and excited state ${ }^{2} \mathrm{~F}_{5 / 2}$ ) and a broad absorption band in the wavelength region of 860-1060 $\mathrm{nm}$ can be a useful sensitizer[11, 12].

In order to develop more efficient fiber lasers for $2.0 \mu \mathrm{m}$ emission, besides the rare earth ions, the host material must be considered as well. Thus, searching for suitable host materials for mid-infrared lasers operating in this wavelength is quite necessary. Recent years have witnessed the great development of various glasses, such as silicate, heavy-metal oxide and fluoride glasses. Although the phonon energy of fluoride-based glass is low, its low mechanical strength limits its applications[13]. In parallel, the low loss and high physical strength of silicate glasses have made them remarkably useful hosts for rare-earth cations emitting in the $2.0 \mu \mathrm{m}$ region. However, compared with other glasses, the larger multiphonon relaxation rate induced by higher phonon energy in silicate glass $\left(\sim 1000 \mathrm{~cm}^{-1}\right)$ 
lowers the quantum efficiency and causes thermal damage of the fiber laser[14]. Thus, the heavy-metal oxide glasses have become a new investigative hotspot of mid-infrared laser to achieve lower phonon energy. Germanate glass as the typical example of heavy-metal oxide glasses, is one of the most promising materials benefited from its high rare-earth solubility, superior infrared transparency, comparative low phonon energy $\left(\sim 900 \mathrm{~cm}^{-1}\right)$, strong mechanical and high damage threshold. Unfortunately, the high cost of $\mathrm{GeO}_{2}$ causes its slow development in optical amplifiers[15-17]. So we try to research mixed germanosilicate (SG) glasses, which can compensate for the deficiencies of silicate and germanate glasses. The phonon energy has been decreased by introducing appropriate amount of $\mathrm{GeO}_{2}$ into silicate glass, which can reduce the multiphonon relaxation rate and enhance the quantum efficiency of $2.0 \mu \mathrm{m}$. Moreover, the addition of $\mathrm{GeO}_{2}$ in silicate host can enhance the refractive index of the glass host and which is beneficial for improving the $2.0 \mu \mathrm{m}$ emission cross section $[18,19]$. Therefore, germanosilicate glass which combines the merits of germanate and silicate glasses can be a suitable optical material for mid-infrared fiber lasers[20].

Additionally, the structure properties of host glasses usually can be modified by tailoring the composition using lanthanide additives. Cations with higher coordination numbers and the higher field strength can enhance the structure of glass and increase glass transition temperature. Lanthanide cations with the high field strength are often used as network modifiers in the glass, which are incorporated in the space between $\mathrm{Si}-(\mathrm{O}, \mathrm{N}) \mathrm{x}$ tetrahedral and strengthen the structure of glass[21]. Therefore, in 1994, Jewell J. et al. reported that the addition of $\mathrm{La}_{2} \mathrm{O}_{3}$ is able to improve glass forming ability and enhance thermal stability due to the larger molecular ratio and coordination number of $\mathrm{La}^{3+}$ ion, while $\mathrm{Y}_{2} \mathrm{O}_{3}$ component is able to improve thermal stability[22]. Since then, many authors have been using lanthanide as the modifier to tailor the optical properties of glasses. For example, in 2017, 
Hao Y. et al. demonstrated the proper introduction of $\mathrm{Y}_{2} \mathrm{O}_{3}$ can enhance the luminescence properties of borosilicate glasses by decreasing the bridge oxygens of glass host[23]. At the same time, Wang X. et al also reported the influence of $\mathrm{La}_{2} \mathrm{O}_{3}$ on the structure and spectroscopy of $\mathrm{Tm}^{3+}$-doped Lanthanum aluminosilicate glasses[24]. Especially, the glass network with $\mathrm{Lu}^{3+}$ would have tighter structure and better properties than the glasses containing other lanthanides owing to its network with smaller atoms.[21]. Additionally, $\mathrm{Lu}^{3+}$ has a stronger ability for bonding with $\mathrm{O}^{2-}$ than $\mathrm{Si}^{4+}$ due to the oxyphilic character of $\mathrm{Lu}^{3+}[25]$. However, there is no detailed report on mid-infrared fluorescence of $\mathrm{Lu}_{2} \mathrm{O}_{3}$ modified germanosilicate glasses from the aspect of regulating its structure.

Thus, in this paper we investigated primarily different concentration of $\mathrm{Lu}_{2} \mathrm{O}_{3}$ in the $\mathrm{Ho}^{3+} / \mathrm{Yb}^{3+}$ co-doped $\mathrm{SiO}_{2}-\mathrm{GeO}_{2}-\mathrm{Ga}_{2} \mathrm{O}_{3}-\mathrm{BaO}-\mathrm{Li}_{2} \mathrm{O}$ (SG) glasses to analysis its structure and mid-infrared spectroscopic properties. The structure of glasses has been studied by X-ray Photoelectron Spectroscopy (XPS) and Raman spectra. The introduction of $\mathrm{Lu}_{2} \mathrm{O}_{3}$ improved the thermal stability and mid-infrared fluorescence in present system. Additionally, we researched the absorption spectra, and then calculated the J-O intensity parameters $\Omega_{\lambda}(\mathrm{t}=2,4,6)$, radiative parameters (such as spontaneous radiation transition probability $\mathrm{A}_{\text {rad}}$, radiation lifetime $\tau_{\text {rad }}$ ) of $\mathrm{Ho}^{3+}$ in present glass. Meanwhile, the absorption $\left(\sigma_{\mathrm{abs}}\right)$ and emission cross sections $\left(\sigma_{\mathrm{em}}\right)$ of $\mathrm{Ho}^{3+}$ at $2.0 \mu \mathrm{m}$ have been calculated and discussed.

\section{Experimental}

Germanosilicate glasses with molar compositions of $(99-\mathrm{x})\left(\mathrm{SiO}_{2}-\mathrm{GeO}_{2}-20 \mathrm{Ga}_{2} \mathrm{O}_{3^{-}}\right.$ $\left.\mathrm{BaO}-\mathrm{Li}_{2} \mathrm{O}\right)-\mathrm{xYb}_{2} \mathrm{O}_{3}-1 \mathrm{Ho}_{2} \mathrm{O}_{3} \quad\left(\mathrm{x}=0\right.$, 1, namely $\mathrm{SG}-\mathrm{Ho}^{3+}$, and $\mathrm{SG}-\mathrm{Ho}^{3+} / \mathrm{Yb}^{3+}$, respectively $)$ and 98( $\left.\mathrm{SiO}_{2}-\mathrm{GeO}_{2}-(20-\mathrm{y}) \mathrm{Ga}_{2} \mathrm{O}_{3}-\mathrm{yLu}_{2} \mathrm{O}_{3}-\mathrm{BaO}-\mathrm{Li}_{2} \mathrm{O}\right)-1 \mathrm{Yb}_{2} \mathrm{O}_{3}-1 \mathrm{Ho}_{2} \mathrm{O}_{3}$ (y=0, 5, 7 and 9, named SG, SGLu5, SGLu7 and SGLu9, respectively) were fabricated by using reagent-grade $\mathrm{SiO}_{2}, \mathrm{GeO}_{2}, \mathrm{Ga}_{2} \mathrm{O}_{3}, \mathrm{BaO}$, 
$\mathrm{Li}_{2} \mathrm{CO}_{3}, \mathrm{La}_{2} \mathrm{O}_{3}, \mathrm{Y}_{2} \mathrm{O}_{3}, \mathrm{Lu}_{2} \mathrm{O}_{3} \mathrm{Yb}_{2} \mathrm{O}_{3}$, and $\mathrm{Ho}_{2} \mathrm{O}_{3}$ as the starting materials. Batches of raw materials $(15 \mathrm{~g})$ were well-mixed and melted in a corundum crucible in a Si-Mo resistance electric furnace at $1520{ }^{\circ} \mathrm{C}$ for $40 \mathrm{~min}$. Then, they were quenched on preheated stainless steel plate and annealed near the temperature of glass transition for $2 \mathrm{~h}$ before they were cooled to room temperature. The annealed samples were finally cut and optically polished to the size of $10 \mathrm{~mm} \times 10 \mathrm{~mm} \times 1 \mathrm{~mm}$ for the optical property measurements.

The characteristic temperatures (temperature of glass transition $T_{g}$ and temperature of onset crystallization peak $\mathrm{T}_{\mathrm{x}}$ ) of samples were determined using a NetzschSTA449/C differential scanning calorimetry at a heating rate of $10 \mathrm{~K} / \mathrm{min}$ with error limit of $\pm 0.2 \%$. The densities of samples were tested via the Archimedes principle using distilled water as the immersion medium with error of \pm 0.001 $\mathrm{g} / \mathrm{cm}^{3}$. Refractive indexes were measured by the prism minimum deviation method at the wavelength of $1053 \mathrm{~nm}$ with error limit of $\pm 0.05 \%$. The visible UC $(500 \sim 800 \mathrm{~nm})$ fluorescence spectra were obtained with a TRIAX550 spectrofluorimeter upon the excitation of $980 \mathrm{~nm}$ LD. Absorption spectra were obtained using a PerkinElmer Lambda 900UV-VIS-NIR spectrophotometer in the range of $300 \sim 2200 \mathrm{~nm}$ a resolution of $1 \mathrm{~nm}$. The emission spectra $(500 \sim 700 \mathrm{~nm}, 1100 \sim 1300 \mathrm{~nm}, 1800 \sim 2300$ $\mathrm{nm}$ and 2700 300 nm) were measured via a Triax 320 type spectrometer upon excitation of $980 \mathrm{~nm}$. The Raman spectra of the glasses were measured with a Renishaw invia Raman microscope in 200-1200 $\mathrm{cm}^{-1}$ spectrum range using the $532 \mathrm{~nm}$ excitation line. The XPS measurements were conducted using a high-performance K-Alpha X-ray photoelectron spectrometer (Thermo Fisher Scientific, United States) in ultra high vacuum. Monochromatic Al Ka radiation (hv=1846.6 eV) was used with $15 \mathrm{kV}$ accelerating voltage. The C-1s peak arising from pump oil impurities was used as an internal reference, with binding energy of $284.6 \mathrm{eV}$. The same experimental conditions for different 
samples were maintained so as to get comparable results. All the measurements were carried out at room temperature. Additionally, the maximal measured error in binding energy is $\pm 0.5 \%$.

\section{Results and discussion}

The Raman spectra of prepared glasses are measured at room temperature as shown in Fig.1. The spectrum of SG glass is deconvoluted into six peaks using Gaussian distribution. These six bands are denoted as $260,465,480,670,840$ and $1020 \mathrm{~cm}^{-1}$ bands. The obvious band $\mathrm{C}$ in Raman spectra is related to bending and stretching vibrations of the T-O-T ( $\mathrm{Ge}$ or $\mathrm{Ga}$ ) bond. The partial vibrations of Ge-O and Ga-O tetrahedron units the peak E is obtained[26]. Hence, in the Raman spectra the contribution of germanate bands is dominate, this is perhaps because of the higher polarizability of $\mathrm{Ge}^{4+}$ than $\mathrm{Si}^{4+}$ and therefore only the primary bands of germanate structures were observed[27, 28]. Especially, from the inset of Fig.1, two weak bands (Peak D and F in the SG glass) at 670 and 1020 $\mathrm{cm}^{-1}$ may be assigned to the Si-O-Ge and Si-O-Si modes[29], and then, the two weak bands exhibit a sharp reduction in the relative intensity with the introduction of the $\mathrm{Lu}_{2} \mathrm{O}_{3}$. A possible mechanism for this reduction is related to the oxyphilic character of $\mathrm{Lu}^{3+}$, and the $\mathrm{Lu}^{3+}$ is preference for bonding with $\mathrm{O}$ exceeds $\mathrm{Si}$, which means that the $\mathrm{Lu}^{3+}$ will compete with $\mathrm{Si}$ for $\mathrm{O}^{2-}[25]$. Hence, in this paper, the introduction of $\mathrm{Lu}_{2} \mathrm{O}_{3}$ instead of $\mathrm{Ga}_{2} \mathrm{O}_{3}$ might break the primary structure of $\left[\mathrm{SiO}_{4}\right] /\left[\mathrm{GeO}_{4}\right]$ and lead a change between the relative amount of $\mathrm{NBO}$ and $\mathrm{BO}$. It will be detailedly researched to further understand the change of glass structure in the next. 


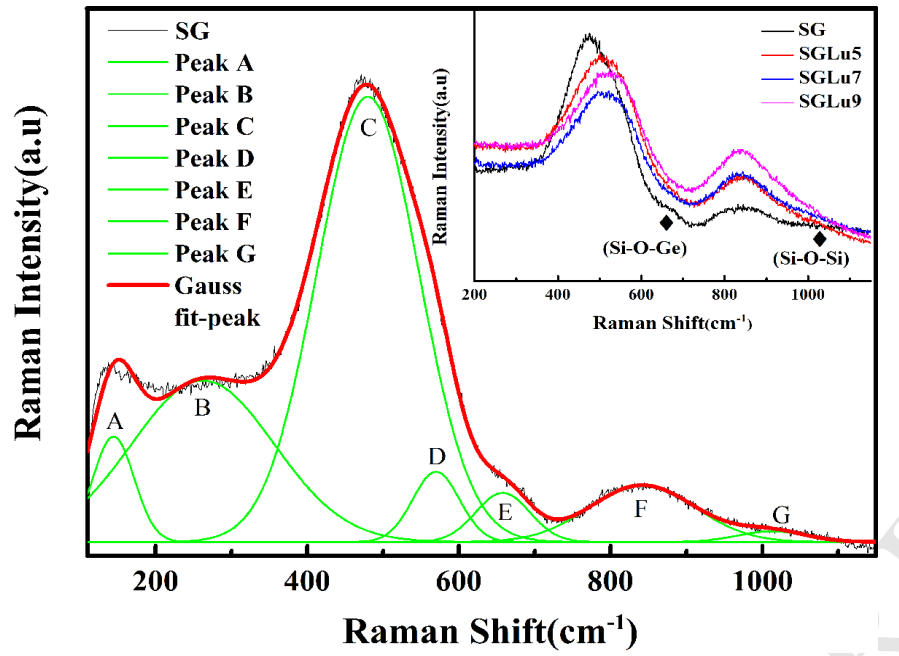

Fig. 1 Deconvoluted Raman spectra of SG glass. The inset is Raman spectra of SG, SGLu5, SGLu7 and SGLu9 glasses.

A detailed analysis of the XPS binding energies was performed in order to get insight into the bonding in these glasses as a function of the rare earth. Fig.2 shows the O1S spectra of present glasses with a Shirley background subtraction. Each spectrum can be deconvoluted into two peaks according to the asymmetry of the shoulders and peaks. The low and high binding energy peaks of O1S spectra of prepared glasses are attributed to non-bridging (NBO) and bridging oxygens (BO), respectively[30, 31$]$. From Table 1, the area fraction F of NBO and BO are $0.33,0.54,0.70$ and 0.71 in SG, SGLu3, SGLu7 and SGLu9 glasses, which suggests that the number of non-bridging oxygens increases in the glass network structures with the introduction of $\mathrm{Lu}_{2} \mathrm{O}_{3}$. A larger non-bridging oxygens number means the structure of primary glass changed and exhibits a lower extent of local $\mathrm{Ho}^{3+}$ clustering in the SGLU-X glasses[32]. Therefore, we can know that the addition of modifier $\mathrm{Lu}_{2} \mathrm{O}_{3}$ in this germanosilicate glass can change the structure of glasses to decrease the probability of rare-earth clustering, conducing to better fluorescence characteristic of germanosilicate glass. 

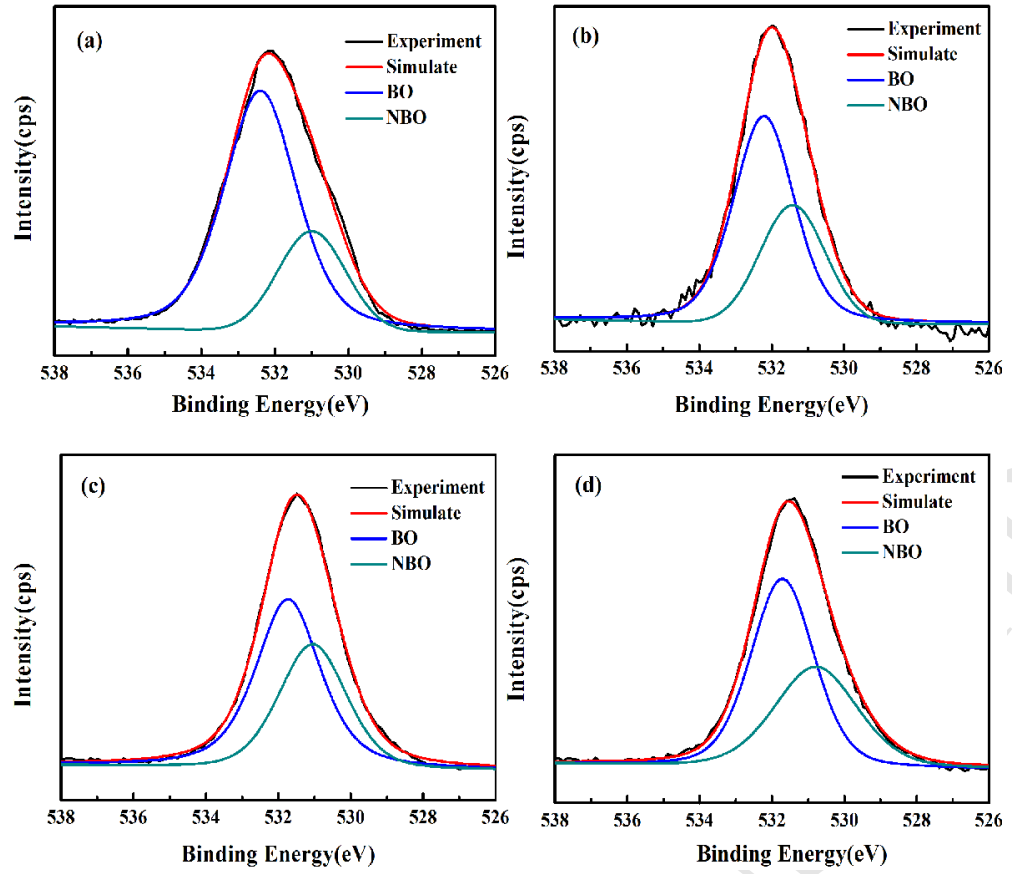

Fig. 2 O1S spectrum of prepared glasses (a) SG; (b) SGLu5; (c) SGLu7; (d) SGLu9.

Table 1 Binding energy (eV), FWHM (eV) and the area ratios F of NBO and BO in XPS spectra.

\begin{tabular}{cccc}
\hline Glass samples & Binding energy $(\mathrm{eV})$ & FWHM $(\mathrm{eV})$ & $\mathrm{F}$ \\
\hline $\mathrm{SG}$ & 532.40 & 2.34 & 0.33 \\
& 531.00 & 2.17 & \\
& 532.21 & 1.98 & 0.54 \\
SGLu5 & 531.42 & 2.11 & \\
& 531.73 & 2.13 & 0.70 \\
SGLu7 & 531.05 & 2.21 & \\
& 531.71 & 2.07 & 0.71 \\
& 530.79 & 2.73 & \\
\hline
\end{tabular}

Fig. 3 shows the measured DSC curves for the prepared glasses. Table 2 lists the characteristic temperatures such as temperature of glass transition $\left(T_{g}\right)$, onset crystallization $\left(T_{x}\right)$ and peak crystallization $\left(\mathrm{T}_{\mathrm{p}}\right)$ as well as the calculated thermal stability parameters $\Delta \mathrm{T}$ in prepared glasses. $\mathrm{T}_{\mathrm{g}}$ is 
an important factor for laser glass, which gives glass good thermal stability to resist thermal damage at high pumping intensities[33]. Meanwhile, $\Delta \mathrm{T}$ has been frequently used for evaluating the thermal stability and forming ability of glass, a larger $\Delta \mathrm{T}$ parameter means the better thermal stability against crystallization and nucleation process. Usually, $\Delta \mathrm{T}$ should be more than $120{ }^{\circ} \mathrm{C}$ to minimize probability of crystallization during the fiber drawing process[34].

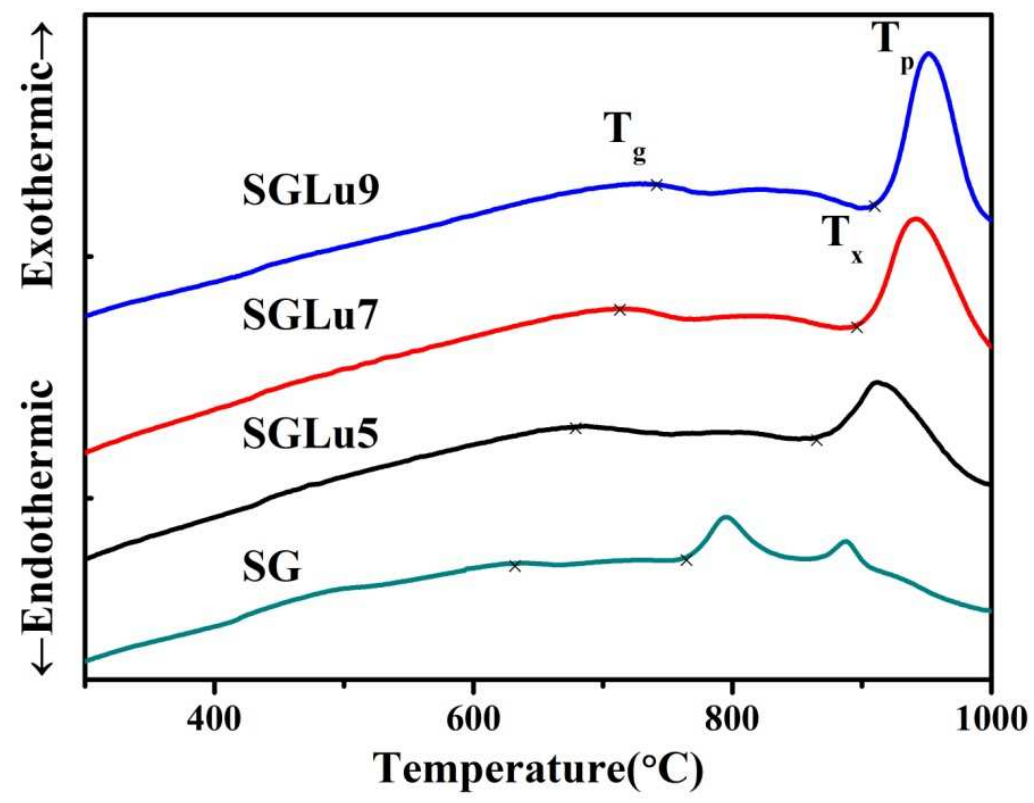

Fig. 3 DSC curves of prepared glasses.

Table 2 The glass transition temperature $\left(T_{g}\right)$, onset crystallization temperature $\left(T_{x}\right)$, top crystallization peak $\left(T_{p}\right)$,

thermal stability parameters $\Delta \mathrm{T}$ in prepared glasses.

\begin{tabular}{ccccc}
\hline Sample & $\mathrm{T}_{\mathrm{g}}\left({ }^{\circ} \mathrm{C}\right)$ & $\mathrm{T}_{\mathrm{x}}\left({ }^{\circ} \mathrm{C}\right)$ & $\mathrm{T}_{\mathrm{p}}\left({ }^{\circ} \mathrm{C}\right)$ & $\Delta \mathrm{T}\left({ }^{\circ} \mathrm{C}\right)$ \\
\hline SG & 645 & 755 & 795 & 110 \\
SGLu5 & 682 & 854 & 911 & 172 \\
SGLu7 & 716 & 896 & 943 & 180 \\
SGLu9 & 730 & 917 & 950 & 187 \\
\hline
\end{tabular}

As shown in Table 2, it can be found the glass transition temperature $\left(\mathrm{T}_{\mathrm{g}}\right)$ increases from $645^{\circ} \mathrm{C}$ to 
$730^{\circ} \mathrm{C}$ which indicates that the introduction of lanthanide cations $\mathrm{Lu}^{3+}$ can improve the thermal stability of this germanosilicate glass system because of so called 'lanthanide contraction' [21]. In addition, the $\Delta \mathrm{T}$ of SGLu5, SGLu7 and SGLu9 are 172,180 and $187^{\circ} \mathrm{C}$, respectively, which are much larger than that of SG glass. These results suggest that the introduction of Lanthanide cations $\mathrm{Lu}^{3+}$ with the high field strength in this germanosilicate glass can be a good way to improve the thermal stability, defined as the resistance to the permanent change of properties, particularly, the resistance against crystallization during heating[35]. Compared with the characteristic temperatures in Table 2 and Fig. 3, a conclusion can be drawn that the prepared germanosilicate glasses with the addition of $\mathrm{Lu}_{2} \mathrm{O}_{3}$ in this study possess a better thermal stability, which is good for crystal-free fiber drawing and fabrication.

Fig. 4 indicates the room temperature absorption spectra of $\mathrm{Ho}^{3+}$ singly and $\mathrm{Yb}^{3+} / \mathrm{Ho}^{3+}$ co-doped samples in the wavelength region of 300-2200 nm. The inset is the photo of prepared glasses. Referring to $\mathrm{Ho}^{3+}$ singly doped SG glass, the absorption spectrum consists of seven absorption bands centered at $1949,1151,644,540,487,474$ and $450 \mathrm{~nm}$, corresponding to the transitions starting from the ${ }^{5} \mathrm{I}_{8}$ ground state to excited states ${ }^{5} \mathrm{I}_{7},{ }^{5} \mathrm{I}_{6},{ }^{5} \mathrm{~F}_{5},\left({ }^{5} \mathrm{~F}_{4},{ }^{5} \mathrm{~S}_{2}\right),\left({ }^{5} \mathrm{G}_{6},{ }^{5} \mathrm{~F}_{1}\right)$ and ${ }^{5} \mathrm{G}_{5}$, respectively. In addition, the broadband absorption with a strong peak at $980 \mathrm{~nm}$ can be observed in $\mathrm{Ho}^{3+} / \mathrm{Yb}^{3+}$ co-doped $\mathrm{SG}$ and SGLUX glasses due to the $\mathrm{Yb}^{3+}:{ }^{2} \mathrm{~F}_{5 / 2}$ transition, otherwise absorption spectra are similar. This suggests that there is no obvious change in the absorb sites of $\mathrm{Ho}^{3+}$ after the introduction of sensitizer $\mathrm{Yb}^{3+}$. It is implied that $\mathrm{Yb}^{3+} / \mathrm{Ho}^{3+}$ co-doped germanosilicate glass can be excited quite efficiently by a conventional $980 \mathrm{~nm} \mathrm{LD}$. 


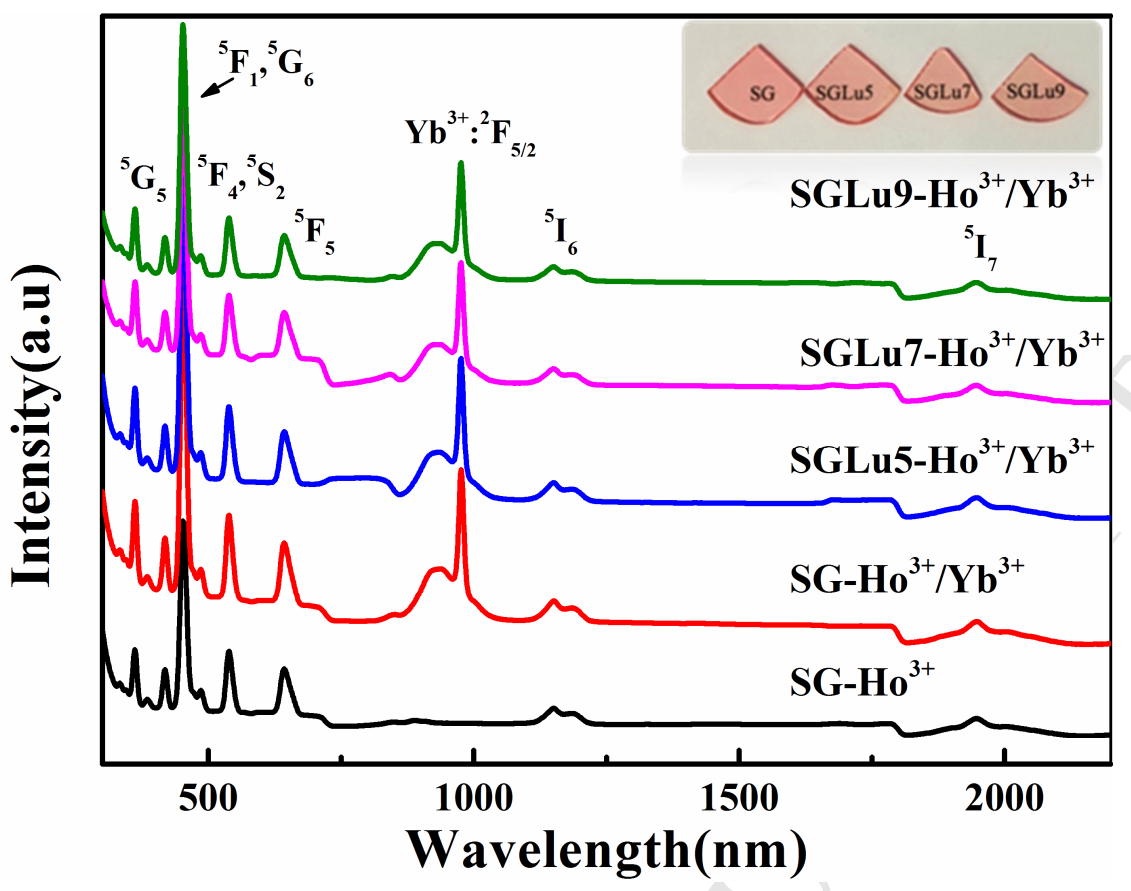

Fig. 4 Absorption spectra of the prepared glasses. The inset is the photo of prepared glasses.

The Judd-Ofelt theory is commonly applied to evaluate the important spectroscopic and laser properties of rare-earth ions doped glasses[36]. According to the J-O theory, absorption spectrum and other parameters, some spectroscopic parameters of rare earths in solids, such as intensity parameters $\Omega_{\lambda}$ radiative transition probability $\mathrm{A}_{\text {rad}}$, and radiative lifetime $\tau_{\text {rad }}$ can be calculated. Table 3 shows the J-O intensity parameters $\left(\Omega_{2}, \Omega_{4}\right.$, and $\left.\Omega_{6}\right)$ of $\mathrm{Ho}^{3+}$ ions in various glass hosts. Previous studies proved that the parameter $\Omega_{2}$ closely depends on the ligand symmetry of local environments of $\mathrm{Ho}^{3+}$ ion sites, and is strongly related to the amount of covalent bonds[37]. As is showed in Table 3, it can be obtained that $\Omega_{2}$ in SGLuX is lower than that of SG glass, the results illustrated that the presence of $\mathrm{Lu}^{3+}$ in the glass structure reduces the covalent of rare earth ions. So, the germanosilicate glass with the addition of $\mathrm{Lu}_{2} \mathrm{O}_{3}$ has lower asymmetry and covalent environment around $\mathrm{Ho}^{3+}$ ions. On the other hand, the $\Omega_{6}$ parameter is a vibronic dependent parameter and the radio of $\Omega_{4} / \Omega_{6}$ determines the spectroscopy quality of the materials[38]. The $\Omega_{4} / \Omega_{6}$ values of prepared glasses are showed in Table 3 . The larger $\Omega_{4} / \Omega_{6}$ value means the higher lasing efficiency for the laser transition of $\mathrm{Ho}^{3+}$ ions in a given matrix. 
From results as shown in Table 3 , it can be found that the $\Omega_{4} / \Omega_{6}$ value increases when the $\mathrm{Lu}_{2} \mathrm{O}_{3}$ is introduced in primal germanosilicate glass host. It turns out that the $\mathrm{Lu}_{2} \mathrm{O}_{3}$ contents in germanosilicate glass can improve the efficiency of laser and be a useful modifier for mid-infrared emission. Besides, the radiative transition probabilities for $\mathrm{Ho}^{3+}:{ }^{5} \mathrm{I}_{7} \rightarrow{ }^{5} \mathrm{I}_{8}$ level can be evaluated via $\mathrm{J}-\mathrm{O}$ parameters. The radiative transition probability $\mathrm{A}_{\mathrm{rad}}$ of prepared sample which possesses highest $\Omega_{4} / \Omega_{6}$ value (SGLu7) is calculated $\left(103.42 \mathrm{~s}^{-1}\right)$, which is larger than those of silicate glass $\left(78.71 \mathrm{~s}^{-1}\right)[39]$ and germanate glass $\left(70.15 \mathrm{~s}^{-1}\right)$ [40]. High spontaneous transition probability is beneficial for high gain and more opportunity to achieve laser action.

Table 3 The J-O intensity parameters $\Omega_{\lambda}(\lambda=2,4,6)\left(\times 10^{-20} \mathrm{~cm}^{2}\right)$ of $\mathrm{Ho}^{3+}$ in prepared glasses.

\begin{tabular}{ccccc}
\hline Sample & $\Omega_{2}$ & $\Omega_{4}$ & $\Omega_{6}$ & $\Omega_{4} / \Omega_{6}$ \\
\hline SG & $5.28 \pm 0.2$ & $3.93 \pm 0.1$ & $1.25 \pm 0.05$ & 3.14 \\
SGLu5 & $5.08 \pm 0.2$ & $3.84 \pm 0.1$ & $1.19 \pm 0.05$ & 3.23 \\
SGLu7 & $4.76 \pm 0.2$ & $3.62 \pm 0.1$ & $1.08 \pm 0.05$ & 3.35 \\
SGLu9 & $4.52 \pm 0.2$ & $3.44 \pm 0.1$ & $1.03 \pm 0.05$ & 3.33 \\
\hline
\end{tabular}

To research the effect of addition of $\mathrm{Lu}_{2} \mathrm{O}_{3}$ on the mid-infrared emission properties in $\mathrm{Ho}^{3+} / \mathrm{Yb}^{3+}$ co-doped germanosilicate glass, the $2.0 \mu \mathrm{m}$ fluorescence spectra of $\mathrm{Ho}^{3+} / \mathrm{Yb}^{3+}$ co-doped SG and SGLU glasses were measured upon 980nm LD and revealed in Fig.5 (a), it can be seen that an obvious emission peak centered near $2.0 \mu \mathrm{m}$ in all samples, which is corresponding to the $\mathrm{Ho}^{3+}:{ }^{5} \mathrm{I}_{7} \rightarrow{ }^{5} \mathrm{I}_{8}$ transition. Meanwhile, the concentrations of $\mathrm{Ho}^{3+} / \mathrm{Yb}^{3+}$ remain unchanged, and it can be found that the relative emission intensity of $2.0 \mu \mathrm{m}$ firstly increases and then decreases with the increasing $\mathrm{Lu}_{2} \mathrm{O}_{3}$ concentration. Additionally, the maximum fluorescence peak intensity for prepared glasses is observed around $7 \mathrm{~mol} \% \mathrm{Lu}_{2} \mathrm{O}_{3}$. Although the $2.0 \mu \mathrm{m}$ emission intensity of SGLu9 decreases, it is still higher 
than original SG glass.
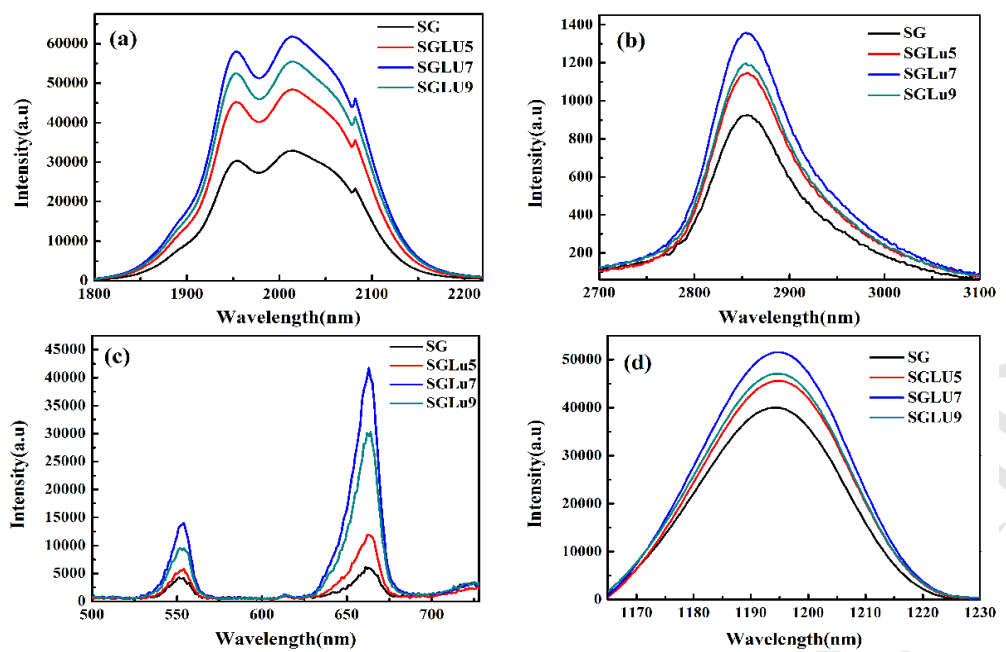

Fig. 5 Fluorescence spectra around (a) $2.0 \mu \mathrm{m}$ (b) $2.8 \mu \mathrm{m}$ (c)up-conversion (d) near-infrared spectra of prepared glasses.

In order to clearly elucidate the $2.0 \mu \mathrm{m}$ emission phenomenon, the $2.8 \mu \mathrm{m}$, near-infrared and up-conversion fluorescence spectra were tested. As shown in Fig. 5(b), (c) and (d), we can find the emissions at $2800,552,652$, and $1200 \mathrm{~nm}$ have the uniform change with the $2000 \mathrm{~nm}$ emission. Therefore, the energy level diagram and energy transfer mechanism of $\mathrm{Ho}^{3+} / \mathrm{Yb}^{3+}$ are showed in Fig.6 so as to further comprehend the relation of mid-infrared $(2.0$ and $2.8 \mu \mathrm{m})$, near-infrared and up-conversion emissions. The electrons of $\mathrm{Yb}^{3+}$ ions at ${ }^{2} \mathrm{~F}_{7 / 2}$ are excited to $\mathrm{Yb}^{3+}:{ }^{2} \mathrm{~F}_{5 / 2}$ by ground state absorption (GSA) when the sample is pumped by $980 \mathrm{~nm} \mathrm{LD}$. Then the energy transfers from the ions on the excited $\mathrm{Yb}^{3+}$ to the ${ }^{5} \mathrm{I}_{6}$ state of $\mathrm{Ho}^{3+}$ by ET: $\mathrm{Ho}^{3+}: \mathrm{I}_{8}+\mathrm{Yb}^{3+}:{ }^{2} \mathrm{~F}_{5 / 2} \rightarrow \mathrm{Ho}^{3+}: \mathrm{I}_{6}+\mathrm{Yb}^{3+}:{ }^{2} \mathrm{~F}_{7 / 2}$. On one hand, some of the electrons at $\mathrm{Ho}^{3+}:{ }^{5} \mathrm{I}_{6}$ level are excited to the ${ }^{5} \mathrm{~F}_{4},{ }^{5} \mathrm{~S}_{2}$ levels by an energy transfer upconversion (ETU1) and excited state absorption (ESA1: ${ }^{5} \mathrm{I}_{6}+\mathrm{a}$ photon $\rightarrow{ }^{5} \mathrm{~F}_{4},{ }^{5} \mathrm{~S}_{2}$ ), the decay of the ions from these states $\left({ }^{5} \mathrm{~F}_{4},{ }^{5} \mathrm{~S}_{2}\right)$ to the ground state $\mathrm{Ho}^{3+}: \mathrm{I}_{8}$ result in the green emission $\left({ }^{5} \mathrm{~F}_{4}\right.$, ${ }^{5} \mathrm{~S}_{2} \rightarrow{ }^{5} \mathrm{I}_{8}+662 \mathrm{~nm}$ ). Due to the small energy gap between ${ }^{5} \mathrm{~F}_{4},{ }^{5} \mathrm{~S}_{2}$ and ${ }^{5} \mathrm{~F}_{5}$ level, ions of ${ }^{5} \mathrm{~F}_{4},{ }^{5} \mathrm{~S}_{2}$ level relax non-radiative to the next ${ }^{5} \mathrm{~F}_{5}$ level, the $552 \mathrm{~nm}$ radiations take place according to the ${ }^{5} \mathrm{~F}_{5} \rightarrow{ }^{5} \mathrm{I}_{8}$ transition. On the other hand, a part of ions on the $\mathrm{Ho}^{3+}:{ }^{5} \mathrm{I}_{6}$ level decay to the next lower $\mathrm{Ho}^{3+}:{ }^{5} \mathrm{I}_{7}$ and ${ }^{5} \mathrm{I}_{8}$ states, 
leading to the 2.8 and $1.2 \mu \mathrm{m}$ emissions, respectively. Finally, the ions in ${ }^{5} \mathrm{I}_{7}$ level decay radiatively to the ground state ${ }^{5} \mathrm{I}_{8}$ and $2.0 \mu \mathrm{m}$ emission occurs. According to Fig.5, it can be obtained that the intensity of $2.8 \mu \mathrm{m}$, near-infrared and up-conversion emissions are in good agreement with the behavior of $2.0 \mu \mathrm{m}$ fluorescence spectra. It might be attributed to the difference of local environment around $\mathrm{Ho}^{3+} / \mathrm{Yb}^{3+}$ ions and, hence, leading to different fluorescence behaviors between SGLUX and SG glasses. It means that a moderate quantity of $\mathrm{Lu}^{3+}$ can decrease clustering of rare-earth $\left(\mathrm{Ho}^{3+}\right)$ ions in this glass, therefore decrease the cross relaxation among rare-earth $\left(\mathrm{Ho}^{3+}\right)$ ions and enhance the emission intensity of $\mathrm{Ho}^{3+}$. Additionally, the maximum fluorescence peak intensity for all fluorescence spectra is observed in SGLu7, which indicates that for fluorescence characteristic the optimum $\mathrm{Lu}_{2} \mathrm{O}_{3}$ adding concentration is around $7 \% \mathrm{~mol}$ in this germanosilicate glass.

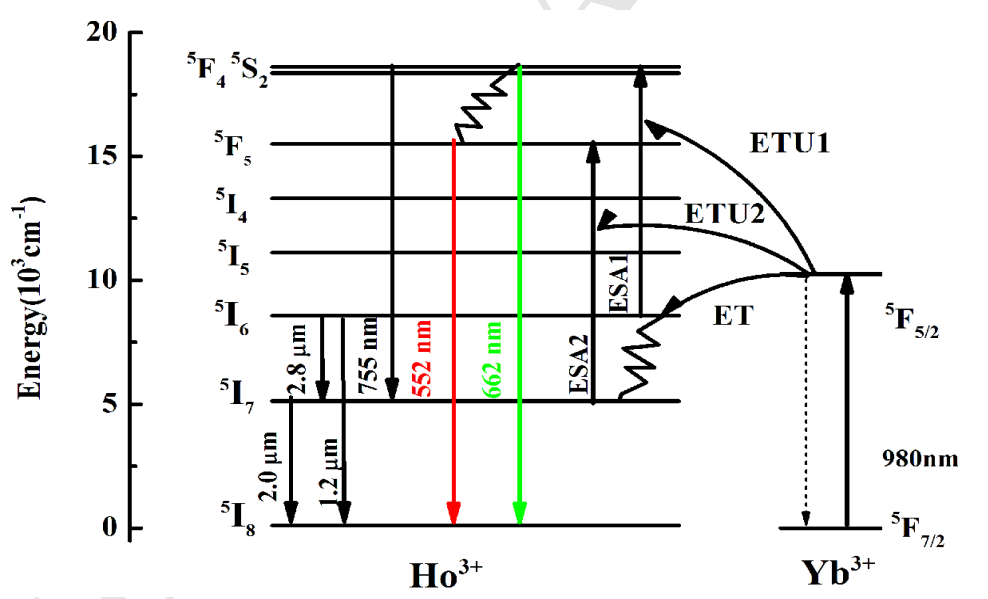

Fig. 6 Energy level diagrams and energy transfer mechanism between $\mathrm{Yb}^{3+}$ and $\mathrm{Ho}^{3+}$ ions.

To research the number of photons involved in the up-conversion luminescence process of this glass, the up-conversion of SGLu7 excited at $980 \mathrm{~nm}$ with different pump power has been measured and shown in Fig.7 (a). The result clearly illustrates that the up-conversion increases with pump power increasing. It is known that for the up-conversion process, the number of photons required to populate the upper emitting state can be described by the following relation[41, 42]

$\mathrm{I} \propto \mathrm{P}^{\mathrm{n}}$ 
where I is the up conversion luminescence intensity, $\mathrm{P}$ is the pump laser intensity, and $\mathrm{n}$ is the number of pump photons required. Fig.7 (b) shows the logarithm-logarithm plots for the up conversion green $(552 \mathrm{~nm})$ and red emission $(662 \mathrm{~nm})$ intensities of SGLu7 as function of excitation power. The plots are well fitted linearly $\left(\mathrm{R}^{2}=0.998\right)$, giving out the slope for ${ }^{5} \mathrm{~F}_{5} \rightarrow{ }^{5} \mathrm{I}_{8}$ and ${ }^{5} \mathrm{~F}_{4} \rightarrow{ }^{5} \mathrm{I}_{8}$ transitions are $1.41 \pm 0.02$ and $1.47 \pm 0.02$, respectively. This indicates that a two-photon absorption process is responsible for the up conversion emission.
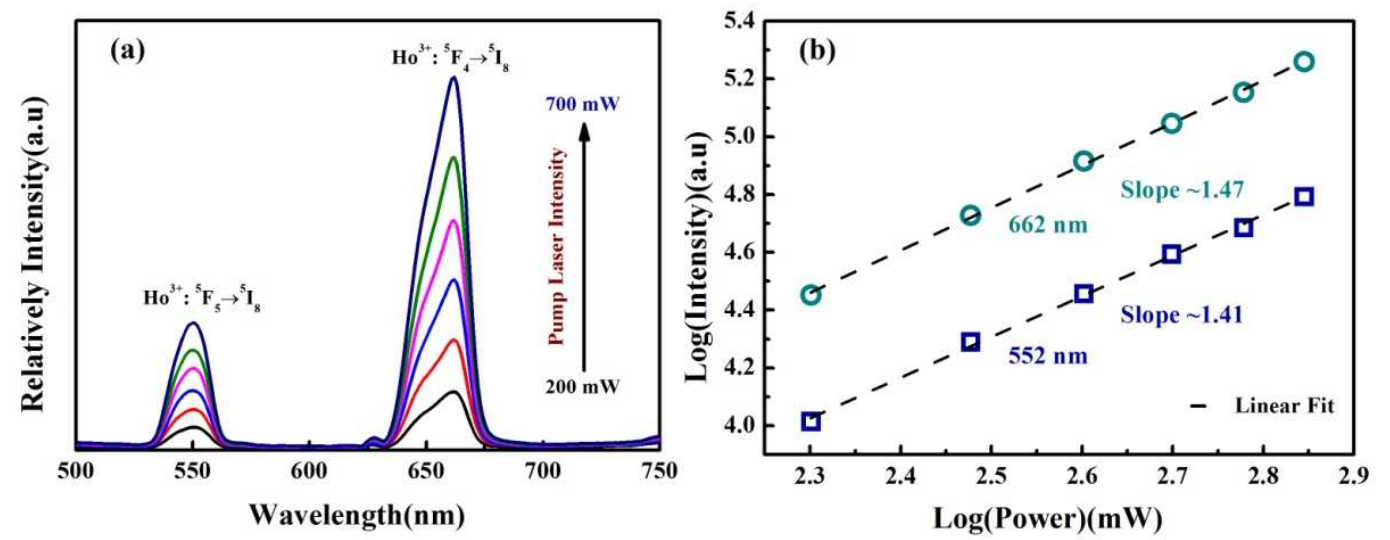

Fig. 7 (a) Up-conversion of SGLu7 excited at $980 \mathrm{~nm}$ with different pump power (mW) in the region of 200-700 nm, (b) Integrated up-conversion intensity at 552 and $662 \mathrm{~nm}$ of SGLu7 vs the pump power.

Fluorescence lifetime is an important parameter to estimate the ions behavior of the excited state. According to the measured and fitted decay curves, the fluorescence lifetime can be determined by the time of the intensity of 1/e. R-square of the single exponential fittings in prepared glass are all above 0.998. The coincidence between the measured and fitted decay curves suggests that energy level ${ }^{5} \mathrm{I}_{7}$ in these glasses single-exponentially. Hence, from Fig.8 and Table.4, it can be found the fluorescence lifetime of $\mathrm{Ho}^{3+}:{ }^{5} \mathrm{I}_{7}$ level becomes longer with increasing $\mathrm{Lu}_{2} \mathrm{O}_{3}$ concentrations. Higher lifetime suggests that the upper level of $2.0 \mu \mathrm{m}$ emission for SGLuX is more favorable for ions accumulation, and SGLuX is more helpful for population inversion between upper level and lower level than SG glass. The lifetime results further proved that the cross relaxation among rare-earth $\left(\mathrm{Ho}^{3+}\right)$ ions has been 
decreased with the addition of $\mathrm{Lu}^{3+}$, and hence, fluorescence lifetime of $\mathrm{Ho}^{3+}:{ }^{5} \mathrm{I}_{7}$ level increased owing to the reduction of multistep energy transfer among rare-earth ions. Moreover, the longer radiation lifetime is beneficial for reducing the laser oscillation threshold[43]. Therefore, this $\mathrm{Ho}^{3+} / \mathrm{Yb}^{3+}$ co-doped germanosilicate glass with the addition of $\mathrm{Lu}_{2} \mathrm{O}_{3}$ can be considered as an appropriate medium to achieve $2.0 \mu \mathrm{m}$ laser.

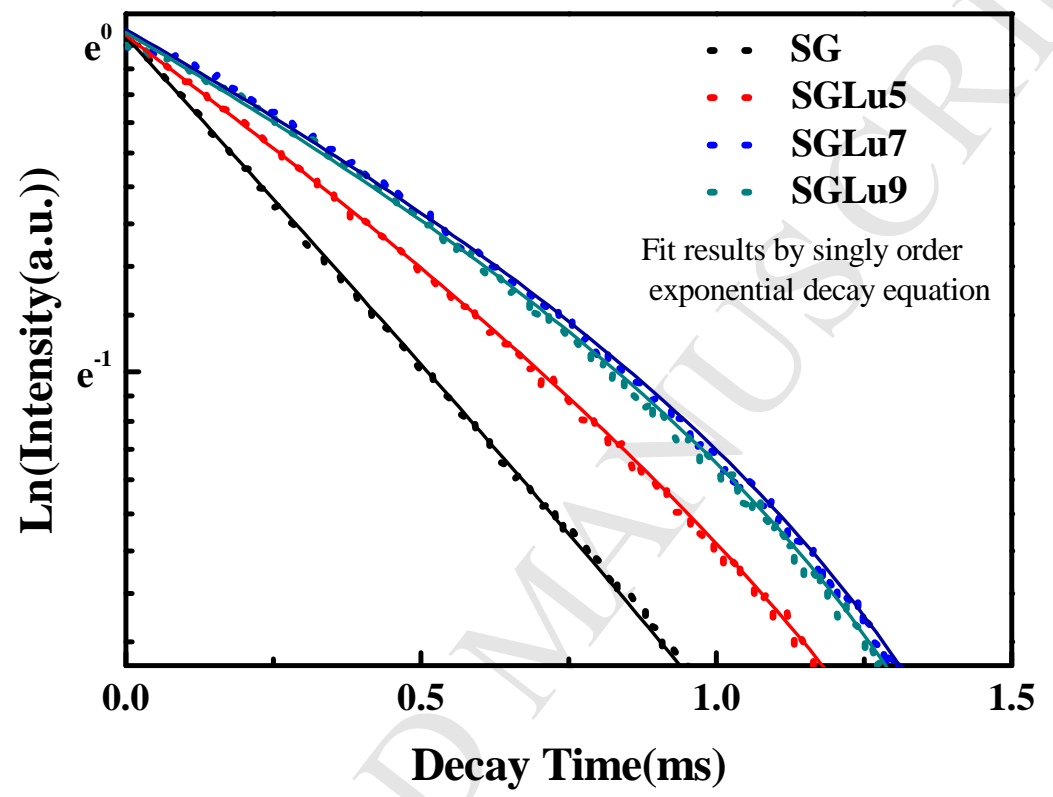

Fig. 8 Decay curves of $2.0 \mu \mathrm{m}$ emission in prepared glasses excited by $980 \mathrm{~nm}$ LD. The solid lines represent the singly fitted decay curves.

Table 4 Measured fluorescence lifetimes of the $\mathrm{Ho}^{3+}:{ }^{5} \mathrm{I}_{7}$ level of prepared glasses.

\begin{tabular}{ccccc}
\hline Sample & SG & SGLu5 & SGLu7 & SGLu9 \\
\hline Lifetime & $485 \mu \mathrm{s}$ & $616 \mu \mathrm{s}$ & $707 \mu \mathrm{s}$ & $691 \mu \mathrm{s}$ \\
\hline
\end{tabular}

The fluorescence decay curves of $\mathrm{Yb}^{3+}$ ions at the wavelength of $1064 \mathrm{~nm}$ in $\mathrm{Yb}^{3+}$ singly, and $\mathrm{Yb}^{3+} / \mathrm{Ho}^{3+}$ co-doped glasses were measured to research the energy transfer process. From Fig.9, it can be found the fluorescence lifetime of $\mathrm{Yb}^{3+}$ becomes longer with the $\mathrm{Lu}_{2} \mathrm{O}_{3}$ addition, which further proved that the cross relaxation among rare-earth ions $\left(\mathrm{Yb}^{3+}\right)$ has been decreased with the addition of $\mathrm{Lu}^{3+}$. Additionally, the fluorescence lifetime of the SG and SGLu7 samples both show obvious 
decrease with the addition of $\mathrm{Ho}^{3+}$. According to the following equation,

$\eta=1-\frac{\tau}{\tau_{0}}$

where $\tau$ and $\tau_{0}$ are the measured lifetimes of $\mathrm{Yb}^{3+}$ with and without the co-doping of $\mathrm{Ho}^{3+}$ ions, respectively. The calculated energy transfer efficiencies of SG and SGLu7 are as high as $73.5 \%$ and $72.6 \%$, respectively, which indicates that the energy transfer from $\mathrm{Yb}^{3+}$ to $\mathrm{Ho}^{3+}$ is efficient. The decrease of energy transfer efficiency might be due to the increase of average distances for $\mathrm{Ho}^{3+}-\mathrm{Yb}^{3+}$.
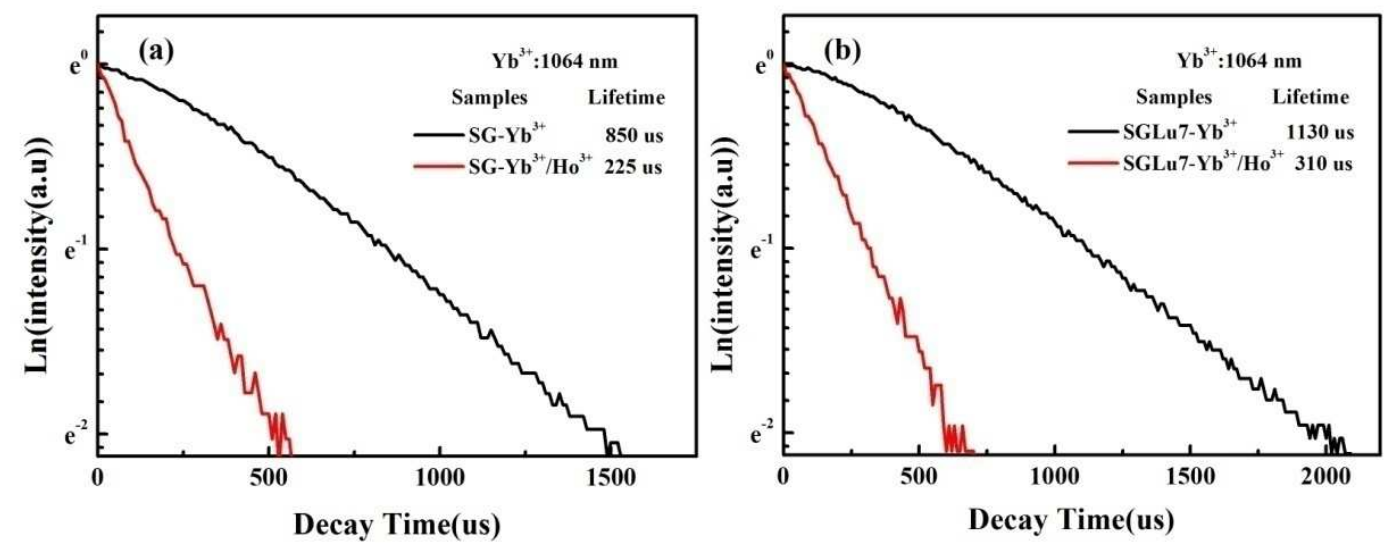

Fig. 9 Decay curves of $1064 \mathrm{~nm}$ emission in prepared glasses excited by $980 \mathrm{~nm}$ LD (a) SG sample,

(b)SGLu7 sample.

The average distance of rare earth ion pairs is related to the cross relaxation and energy transfer among rare earth ions. Hence, the average distance for $\mathrm{Ho}^{3+}-\mathrm{Ho}^{3+}$ and $\mathrm{Yb}^{3+}-\mathrm{Ho}^{3+}$ are counted using the following equation[44]

$$
\mathrm{R}_{\mathrm{i}}=\left(\frac{\mathrm{M}}{\mathrm{N}_{\mathrm{A}} \mathrm{X}}\right)^{1 / 3}
$$

where $\mathrm{N}_{\mathrm{A}}$ is the Avogadro number, $\rho$ is the density of prepared glass, $\mathrm{M}$ is the mean molecular weight of glass, and $\mathrm{x}$ is the total concentration of the $\mathrm{Yb}^{3+}-\mathrm{Ho}^{3+}$ or $\mathrm{Ho}^{3+}-\mathrm{Ho}^{3+}$ ions. The calculated values are listed in Table 5. The change of average distances is in line with the above discussion. The increasing average distance of $\mathrm{Yb}^{3+}-\mathrm{Ho}^{3+}$ slightly decreases the energy transfer efficiency. However, the 
increasing average distance of $\mathrm{Ho}^{3+}-\mathrm{Ho}^{3+}$ also results in the decrease of cross relaxation, which can enhance the fluorescence emission of $\mathrm{Ho}^{3+}$ ions.

Based on the above results, the ideal net structure diagram of the prepared glasses in short range has been proposed as shown in Fig.10.

Table 5 The average distances of $\mathrm{Yb}^{3+}-\mathrm{Ho}^{3+}$ or $\mathrm{Ho}^{3+}-\mathrm{Ho}^{3+}$ ion pairs

\begin{tabular}{ccccc}
\hline Average distance $(\AA)$ & SG & SGLu5 & SGLu7 & SGLu9 \\
\hline $\mathrm{Yb}^{3+}-\mathrm{Ho}^{3+}$ & 10.48 & 10.60 & 10.69 & 10.77 \\
$\mathrm{Ho}^{3+}-\mathrm{Ho}^{3+}$ & 13.20 & 13.35 & 13.47 & 13.57 \\
\hline
\end{tabular}

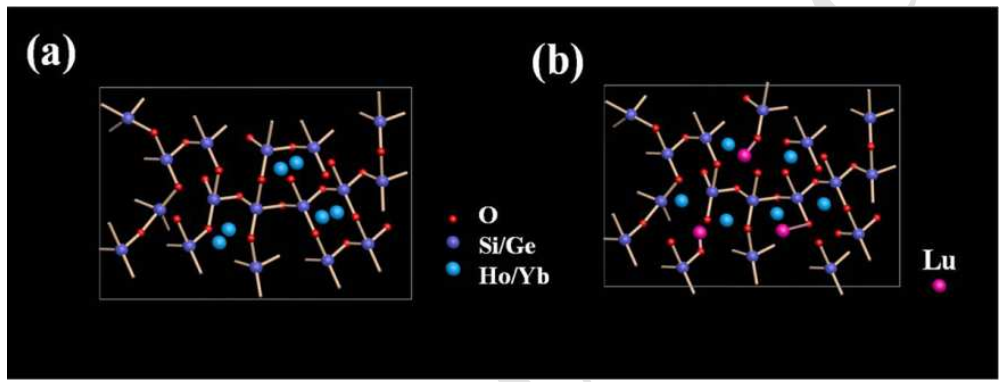

Fig. 10 The ideal net structure diagram of the prepared glasses in short range (a) without $\mathrm{Lu}_{2} \mathrm{O}_{3}$ (b) with $\mathrm{Lu}_{2} \mathrm{O}_{3}$.

From the discussions above, we can conclude that SGLu7 possesses optimal fluorescence characteristic. So we calculated the absorption, emission and gain cross sections of SGLu7 sample in order to further research its possibility as mid-infrared laser material. The emission cross section $\left(\sigma_{\mathrm{em}}\right)$ of $2.0 \mu \mathrm{m}$ fluorescence spectra can be calculated according to Fuchtbauer-Ladenburg equation[45]

$\sigma_{e m}(\lambda)=\frac{\lambda^{4} A_{r a d}}{8 \pi c n^{2}} \times \frac{\lambda I(\lambda)}{\int \lambda I(\lambda) d \lambda}$

where $A_{\text {rad }}$ is the spontaneous radiative transition probability of $\mathrm{Ho}^{3+}:{ }^{5} \mathrm{I}_{7} \rightarrow{ }^{5} \mathrm{I}_{8}$ transition, $\lambda$ is the emission wavelength, $\mathrm{n}$ is the refractive index of glass host, $\mathrm{c}$ is the velocity of light in vacuum, $\int \mathrm{I}(\lambda) \mathrm{d} \lambda$ is the integrated fluorescence intensity, and $\mathrm{I}(\lambda)$ is the $2.0 \mu \mathrm{m}$ fluorescence spectra intensity.

Based on emission cross section, absorption cross section can be obtained by using the 
McCumber (MC) formula[46]

$\sigma_{e m}(\lambda)=\sigma_{a b s}(\lambda) \times \frac{Z_{l}}{Z_{u}} \times \exp \left[\frac{h c}{k t} \times\left(\frac{1}{\lambda_{Z L}}-\frac{1}{\lambda}\right)\right]$

where $Z_{l}$ and $Z_{u}$ are the respective partition functions of the lower and the upper levels involved in the considered optical transition is equal to $17 / 15$. Parameter $\mathrm{K}$ and $\mathrm{T}$ are the Boltzmann constant (1.38 $\times 10^{-23} \mathrm{~J} / \mathrm{K}$ ) and the temperature (here it is the room temperature), respectively. $\lambda_{\mathrm{ZL}}=2014 \mathrm{~nm}$ is the zero-phonon line which means the wavelength for the transition between the lower Stark sublevels of the emitting multiplets and the lower Stark sublevels of the receiving multiplets.

The absorption and emission cross sections of $\mathrm{Ho}^{3+}$ in SGLu7 sample are shown in Fig.11 (a). It can be seen that the maximum emission cross section $\sigma_{\mathrm{em}}$ for $\mathrm{Ho}^{3+}:{ }^{5} \mathrm{I}_{7} \rightarrow{ }^{5} \mathrm{I}_{8}$ is $4.41 \times 10^{-21} \mathrm{~cm}^{2}$ at $2022 \mathrm{~nm}$, which is higher than those of germanate-tellurite $\left(4.36 \times 10^{-21} \mathrm{~cm}^{2}\right)[47]$ and silicate $\left(3.07 \times 10^{-21} \mathrm{~cm}^{2}\right)[48]$ glasses. Thereby, the prepared SGLu7 glass possessing higher emission cross section might be a superior laser material for achieving intense $2.0 \mu \mathrm{m}$ laser.

In addition, gain coefficient is another characteristic parameter to evaluate $2.0 \mu \mathrm{m}$ emission properties quantitatively. Therefore, the gain spectra $G(\lambda)$ can be calculated by

$G(\lambda)=N\left[P \sigma_{e m}(\lambda)-(1-P) \sigma_{a b s}(\lambda)\right]$

where $\mathrm{P}$ is the population inversion given by the ratio between the population of $\mathrm{Ho}^{3+}: \mathrm{I}_{7}$ level and the total $\mathrm{Ho}^{3+}$ concentration and $\mathrm{N}$ is the total concentration of $\mathrm{Ho}^{3+}$ Fig.11 (b) indicates the gain spectra of $2.0 \mu \mathrm{m}$ of SGLu7 glasses. Obviously, when the population inversion $\mathrm{P}>0.4$, the gain cross sections in the range of $1700-2300 \mathrm{~nm}$ become positive. It is suggested that the prepared $\mathrm{Ho}^{3+} / \mathrm{Yb}^{3+}$ co-doped SGLu7 glass would be a suitable optical material to obtain $2.0 \mu \mathrm{m}$ infrared emission thanks to the excellent gain properties. 

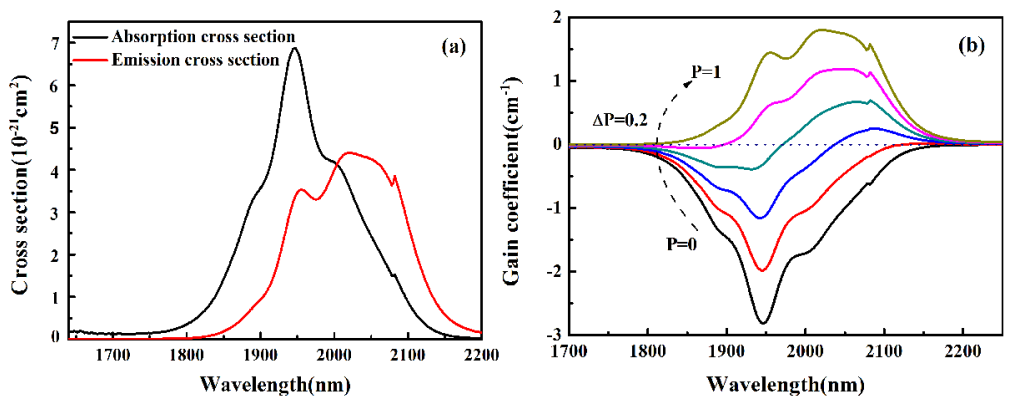

Fig. 11 (a) The calculated absorption and emission cross sections (b) gain coefficient for prepared glass (SGLu7).

\section{Conclusions}

This study investigated the structure and fluorescence characteristic in the $\mathrm{Ho}^{3+} / \mathrm{Yb}^{3+}$ co-doped germanosilicate glasses by using lanthanide additives $\mathrm{Lu}_{2} \mathrm{O}_{3}$. The introduction of $\mathrm{Lu}_{2} \mathrm{O}_{3}$ improves the thermal stability of glass system owing to the oxyphilic character of Lanthanide cations $\mathrm{Lu}^{3+}$. And $\mathrm{Lu}_{2} \mathrm{O}_{3}$ changes the structure of glass to decrease the probability of rare-earth clustering $\left(\mathrm{Ho}^{3+}\right)$, conducing to the fluorescence characteristic of germanosilicate glass. Meanwhile, the J-O intense parameters and radiative lifetimes of $\mathrm{Ho}^{3+} / \mathrm{Yb}^{3+}$ co-doped germanosilicate glass with different concentration $\mathrm{Lu}_{2} \mathrm{O}_{3}$ are calculated and discussed. The results of test and discussion indicate that SGLu7 possesses optimal fluorescence characteristic. The emission cross section at $2.0 \mu \mathrm{m}$ reaches as high as $4.41 \times 10^{-21} \mathrm{~cm}^{2}$ in SGLu7 glass. According to the experimental results, the germanosilicate glass with the modification of $\mathrm{Lu}_{2} \mathrm{O}_{3}$ might be a promising candidate for $2.0 \mu \mathrm{m}$ laser.

\section{Acknowledgements}

This research was financially supported by the Chinese National Natural Science Foundation (Nos. 61605192, and 51472225), the Natural Science Foundation of Zhejiang Province (LY18E020008), and the open Fund of the Guangdong Engineering Technology Research Development Center of Special Optical Fiber Materials and Devices (South China University of Technology). 


\section{References}

[1] J. Geng, Q. Wang, Z. Jiang, T. Luo, S. Jiang, G. Czarnecki, Kilowatt-peak-power, single-frequency, pulsed fiber laser near $2 \mu \mathrm{m}$, Opt. Lett. 36 (2011) 2293-2295.

[2] Z. Zheng, D. Ouyang, J. Zhao, M. Liu, S. Ruan, P. Yan, J. Wang, Scaling all-fiber mid-infrared supercontinuum up to $10 \mathrm{~W}$-level based on thermal-spliced silica fiber and ZBLAN fiber, Photon. Res. 4 (2016) 135-139.

[3] F. Qi, F. Huang, L. Zhou, Y. Tian, R. Lei, G. Ren, J. Zhang, L. Zhang, S. Xu, Long lifetime of $\mathrm{Er}^{3+}$ : ${ }^{4} \mathrm{I}_{11 / 2}$ in low phonon-energy fluoro-chloride glasses for mid-infrared optical applications, J. Alloys Compd. 731 (2018) 418-422.

[4] Y. Sun, Q. Yang, H. Wang, Q. Zhang, Y. Shao, Preparation and mid-infrared 2.7 $\mu \mathrm{m}$ luminescence property of high content $\mathrm{Er}^{3+}$-doped $\left(\mathrm{Y}_{0.9} \mathrm{La}_{0.1}\right)_{2} \mathrm{O}_{3}$ transparent ceramics pumped at $980 \mathrm{~nm}$, Ceram. Int. 44 (2018) 1812-1816.

[5] A. Yang, J. Qiu, M. Zhang, H. Ren, C. Zhai, S. Qi, B. Zhang, D. Tang, Z. Yang, Mid-infrared luminescence of $\mathrm{Dy}^{3+}$ ions in modified Ga-Sb-S chalcogenide glasses and fibers, J. Alloys Compd. 695 (2017) 1237-1242.

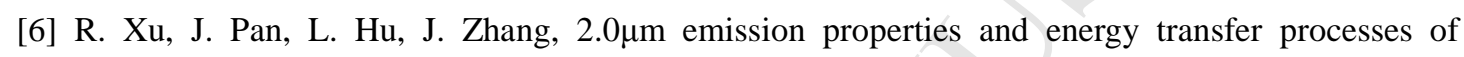
$\mathrm{Yb}^{3+} / \mathrm{Ho}^{3+}$ codoped germanate glass, J. Appl. Phys. 108 (2010) 043522.

[7] W. Li, D. Chen, Q. Zhou, L. Hu, Watt-level output rectangular-core neodymiun-doped silicate glass fiber laser, Chin. Opt. Lett. 14 (2016) 01140201-01140203.

[8] G. Bai, Y. Guo, Y. Tian, L. Hu, J. Zhang, Light emission at $2 \mu \mathrm{m}$ from Ho-Tm-Yb doped silicate glasses, Opt. Mater. 33 (2011) 1316-1319.

[9] G. Gao, L. Hu, H. Fan, G. Wang, K. Li, S. Feng, S. Fan, H. Chen, J. Pan, J. Zhang, Investigation of $2.0 \mu \mathrm{m}$ emission in $\mathrm{Tm}^{3+}$ and $\mathrm{Ho}^{3+}$ co-doped $\mathrm{TeO}_{2}-\mathrm{ZnO}_{-} \mathrm{Bi}_{2} \mathrm{O}_{3}$ glasses, Opt. Mater. 32 (2009) 402-405.

[10] M. Li, Y. Guo, G. Bai, Y. Tian, L. Hu, J. Zhang, $\sim 2 \mu \mathrm{m}$ Luminescence and energy transfer characteristics in $\mathrm{Tm}^{3+} / \mathrm{Ho}^{3+}$ co-doped silicate glass, J. Quant. Spectrosc. Radiat. Trans. 127 (2013) 70-77.

[11] B. Zhou, L. Tao, C. Yat-Yin Chan, W. Jin, Y.H. Tsang, E. Yue-Bun Pun, Near- and mid-infrared photoluminescence in $\mathrm{Ho}^{3+}$ doped and $\mathrm{Ho}^{3+}-\mathrm{Yb}^{3+}$ codoped low-phonon-energy germanotellurite glasses, J. Lumin. 137 (2013) 132-137.

[12] S. Ye, J. Song, D. Wang, Y. Tian, J. Qu, H. Niu, Reduced photon quenching in Ce-doped $\mathrm{NaYF}_{4}: \mathrm{Yb} / \mathrm{Ho}$ upconversion nanoparticles with core/shell structure, Opt. Lett. 14 (2016) 21601-21605.

[13] D. He, S. Kang, L. Zhang, L. Chen, Y. Ding. Q. Yin, L. Hu, Research and development of new neodymium laser glass, High Power Laser Sci. Eng. 5 (2017) e1

[14] M. Li, G. Bai, Y. Guo, L. Hu, J. Zhang, Investigation on $\mathrm{Tm}^{3+}$-doped silicate glass for $1.8 \mu \mathrm{m}$ emission, J. Lumin. 132 (2012) 1830-1835.

[15] G. Bai, L. Tao, K. Li, L. Hu, Y.H. Tsang, Enhanced light emission near $2.7 \mu \mathrm{m}$ from Er-Nd co-doped germanate glass, Opt. Mater. 35 (2013) 1247-1250.

[16] S.S. Bayya, G.D. Chin, J.S. Sanghera, I.D. Aggarwal, Germanate glass as a window for high energy laser systems, Opt. Express. 14 (2006) 11687-11693.

[17] W.J. Zhang, Q.J. Chen, J.P. Zhang, Q. Qian, Q.Y. Zhang, L. Wondraczek, Enhanced NIR emission from nanocrystalline $\mathrm{LaF}_{3}: \mathrm{Ho}^{3+}$ germanate glass ceramics for E-band optical amplification, J. Alloys Compd. 541 (2012) 323-327.

[18] S.S. Bayya, G.D. Chin, G. Villalobos, J.S. Sanghera, I.D. Aggarwal, VIS-IR transmitting windows, 
Proc. SPIE 5786 (2005) 262-271.

[19] T. Wei, F. Chen, Y. Tian, S. Xu, Broadband $1.53 \mu \mathrm{m}$ emission property in $\mathrm{Er}^{3+}$ doped germa-silicate glass for potential optical amplifier, Opt. Commun. 315 (2014) 199-203.

[20] T. Wei, C. Tian, M. Cai, Y. Tian, X. Jing, J. Zhang, S. Xu, Broadband $2 \mu \mathrm{m}$ fluorescence and energy transfer evaluation in $\mathrm{Ho}^{3+} / \mathrm{Er}^{3+}$ codoped germanosilicate glass, J. Quant. Spectrosc. Radiat. Trans. 161 (2015) 95-104.

[21] F. Lofaj, R. Satet, M.J. Hoffmann, A.R. de Arellano López, Thermal expansion and glass transition temperature of the rare-earth doped oxynitride glasses, J. Eur. Ceram. Soc. 24 (2004) 3377-3385.

[22] J. M. Jewell, P.L. Higby, I.D. Aggarwal, Properties of $\mathrm{BaO}-\mathrm{R}_{2} \mathrm{O}_{3}-\mathrm{Ga}_{2} \mathrm{O}_{3}-\mathrm{GeO}_{2}(\mathrm{R}=\mathrm{Y}$, Al, La, and Gd) Glasses, J. Am. Ceram. Soc. 77 (1994) 697-700.

[23] Y. Hao, Y. Dai, Influence of $\mathrm{Y}_{2} \mathrm{O}_{3}$ on the structure and luminescence of $\mathrm{Eu}^{2+}$ doped borosilicate glasses, J. Non-Cryst. Solids. 474 (2017) 32-36.

[24] X. Wang, S. Kang, S. Fan, S. Wang, C. Yu, D. Chen, L. Hu, Influence of La/Al ratio on the structure and spectroscopy of $\mathrm{Tm}^{3+}$ doped $\mathrm{Al}_{2} \mathrm{O}_{3}-\mathrm{La}_{2} \mathrm{O}_{3}-\mathrm{SiO}_{2}$ glasses, J. Alloys Compd. 690 (2017) 583-588.

[25] V. Fouquet-Parry, F. Paumier, M.J. Guittet, M. Gautier-Soyer, R. Satet, M.J. Hoffmann, P.F. Becher, G.S. Painter, Composition and local bonding in RE-Si-M-O-N (M=Mg, Al ; RE=La, Lu) glasses, Appl. Surf. Sci. 254 (2008) 4665-4670.

[26] T. Wang, F. Huang, F. Qi, Y. Tian, J. Zhang, S. Xu, Spectroscopic properties and energy transfer process in $\mathrm{Tm}^{3+}$-doped Silica-germanate glasses, J. Lumin. 187 (2017) 205-210.

[27] H. Verweij, Raman study of the structure of alkali germanosilicate glasses (I): Sodium and potassium metagermanosilicate glasses, J. Non-Cryst. Solids. 33 (1979) 41-53.

[28] R. Chen, Y. Tian, B. Li, X. Jing, J. Zhang, S. Xu, H. Eckert, X. Zhang, Thermal and luminescent properties of $2 \mu \mathrm{m}$ emission in thulium-sensitized holmium-doped silicate-germanate glass, Photon. Res. 4 (2016) 214-221.

[29] S.K. Sharma, D.W. Matson, J.A. Philpotts, T.L. Roush, Raman study of the structure of glasses along the join $\mathrm{SiO}_{2}-\mathrm{GeO}_{2}$, J. Non-Cryst. Solids. 68 (1984) 99-114.

[30] B.V.R. Chowdari, Z. Rong, The role of $\mathrm{Bi}_{2} \mathrm{O}_{3}$ as a network modifier and a network former in $\mathrm{xBi}_{2} \mathrm{O}_{3} \cdot(1-\mathrm{x}) \mathrm{LiBO}_{2}$ glass system, Solid State Ionics. 90 (1996) 151-160.

[31] T. Honma, R. Sato, Y. Benino, T. Komatsu, V. Dimitrov, Electronic polarizability, optical basicity and XPS spectra of $\mathrm{Sb}_{2} \mathrm{O}_{3}-\mathrm{B}_{2} \mathrm{O}_{3}$ glasses, J. Non-Cryst. Solids. 272 (2000) 1-13.

[32] L. Wang, L. Tan, Y. Yue, M. Peng, J. Qiu, Efficient Enhancement of Bismuth NIR Luminescence by Aluminum and Its Mechanism in Bismuth-Doped Germanate Laser Glass, J. Am. Ceram. Soc. 99 (2016) 2071-2076.

[33] N.H. Chan, R.K. Sharma, D.M. Smyth, Nonstoichiometry in Acceptor-Doped $\mathrm{BaTiO}_{3}$, J. Am. Ceram. Soc. 65 (1982) 167-170.

[34] Z. Yang, T. Luo, S. Jiang, J. Geng, P. Lucas, Single-mode low-loss optical fibers for long-wave infrared transmission, Opt. Lett. 35 (2010) 3360-3362.

[35] B. Burtan-Gwizdala, M. Reben, J. Cisowski, R. Lisiecki, W. Ryba-Romanowski, B. Jarzabek, Z. Mazurak, N. Nosidlak, I. Grelowska, The influence of $\operatorname{Pr}^{3+}$ content on luminescence and optical behavior of $\mathrm{TeO}_{2}-\mathrm{WO}_{3}-\mathrm{PbO}-\mathrm{Lu}_{2} \mathrm{O}_{3}$ glass, Opt. Mater. 47 (2015) 231-236.

[36] B.R. Judd, Optical Absorption Intensities of Rare-Earth Ions, Phys. Rev. 127 (1962) 750-761.

[37] M. Wang, L. Yi, G. Wang, L. Hu, J. Zhang, emission performance in $\mathrm{Ho}^{3+}$ doped fluorophosphate glasses sensitized with $\mathrm{Er}^{3+}$ and $\mathrm{Tm}^{3+}$ under $800 \mathrm{~nm}$ excitation, Solid State Commun. 149 (2009) 
1216-1220.

[38] P.R. Watekar, S. Ju, W.T. Han, Optical properties of Ho-doped alumino-germano-silica glass optical fiber, J. Non-Cryst. Solids. 354 (2008) 1453-1459.

[39] R. Cao, M. Cai, Y. Lu, Y. Tian, F. Huang, S. Xu, J. Zhang, $\mathrm{Ho}^{3+} / \mathrm{Yb}^{3+}$ codoped silicate glasses for 2 $\mu \mathrm{m}$ emission performances, Appl. Opt. 55 (2016) 2065-2070.

[40] J. Fan, Y. Fan, Y. Yang, D. Chen, L. Calveza, X. Zhang, L. Zhang, Spectroscopic properties and

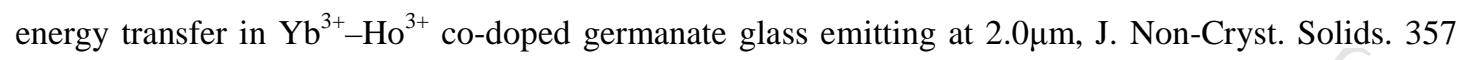
(2011) 2431-2434.

[41] Z. Dong, T. Wei, Y.J. Ma, T.B. Zhang, X.X. Lian, Y.Y. Guo, F.M. Yang, D.M. An, Influence of erbium substitution on structural, electrical, and up-conversion photoluminescence properties of unfilled tungsten bronze oxides $\mathrm{Ba}_{3.75} \mathrm{La}_{0.833-\mathrm{x}} \mathrm{Er}_{\mathrm{x}} \mathrm{Nb}_{10} \mathrm{O}_{30}$, J. Alloys Compd. 681 (2016) 240-252.

[42] C. Zhao, X. Kong, X. Liu, L. Tu, F. Wu, Y. Zhang, K. Liu, Q. Zeng, H. Zhang, $\mathrm{Li}^{+}$ion doping: an approach for improving the crystallinity and upconversion emissions of $\mathrm{NaYF}_{4}: \mathrm{Yb}^{3+}, \mathrm{Tm}^{3+}$ nanoparticles, Nanoscale. 5 (2013) 8084-8089.

[43] T. Wei, Y. Tian, F. Chen, M. Cai, J. Zhang, X. Jing, F. Wang, Q. Zhang, S. Xu, Mid-infrared fluorescence, energy transfer process and rate equation analysis in $\mathrm{Er}^{3+}$ doped germanate glass, Sci. Rep. 4 (2014) 6060.

[44] X.Y. Sun, D.G. Jiang, Y.Z. Sun, X. Zhang, Q.L. Hu, Y. Huang, Y. Tao, Eu ${ }^{3+}$-activated $\mathrm{B}_{2} \mathrm{O}_{3}-\mathrm{GeO}_{2}-\mathrm{RE}_{2} \mathrm{O}_{3}\left(\mathrm{RE}=\mathrm{Y}^{3+}, \mathrm{La}^{3+}\right.$ and $\left.\mathrm{Gd}^{3+}\right)$ borogermanate scintillating glasses, J. Non-Cryst. Solids. 389 (2014) $72-77$.

[45] S.A. Payne, L.L. Chase, L.K. Smith, W.L. Kway, W.F.E.D.B.J.G.A.H.T. Krupke, W. Krupke, Infrared cross-section measurements of the $\mathrm{Er}^{3+}, \mathrm{Tm}^{3+}$, and $\mathrm{Ho}^{3+}$ ions in crystals, Conference on Lasers and Electro-Optics, 28 (1991) 2619-2630.

[46] F. Qi, F. Huang, T. Wang, R. Lei, J. Zhang, S. Xu, L. Zhang, Influence of $\mathrm{Tm}^{3+}$ ions on the amlification of $\mathrm{Ho}^{3+}: \mathrm{I}_{7}{ }^{-5} \mathrm{I}_{8}$ transition in fluoride glass modified by $\mathrm{Al}\left(\mathrm{PO}_{3}\right)_{3}$ for applications in mid-inrared optics, Chin. Opt. Lett. 15 (2017) 05160401-05160406.

[47] Y. Peng, Y. Guo, J. Zhang, L. Zhang, $\mathrm{Ho}^{3+} / \mathrm{Yb}^{3+}$-codoped germanate-tellurite glasses for $2.0 \mu \mathrm{m}$ emission performance, Appl. Opt. 53 (2014) 1564-1569.

[48] M. Li, Y. Guo, G. Bai, Y. Tian, L. Hu, J. Zhang, $\sim 2 \mu \mathrm{m}$ Luminescence and energy transfer characteristics in $\mathrm{Tm}^{3+} / \mathrm{Ho}^{3+}$ co-doped silicate glass, J. Quant. Spectrosc. Radiat. Trans. 127 (2013) $70-77$. 


\section{Highlights:}

1. Structural and fluorescence properties of germanosilicate glasses were researched.

2. The addition of $\mathrm{Lu}_{2} \mathrm{O}_{3}$ increases $\Delta \mathrm{T}$ to improve the thermal stability of glass host.

3. The increase of NBO can decrease the cross relaxation effect among RE-RE ions.

4. Fluorescence properties of $\mathrm{Ho}^{3+}$ have been improved due to the increase of NBO. 